DOI: https://doi.org/10.24127/ajpm.v9i2.2796

\title{
PENGEMBANGAN MODUL PANDUAN GURU MATEMATIKA DALAM MENDESAIN PEMBELAJARAN PjBL BERBASIS BUDAYA JAMBI
}

\author{
Kamid $^{1 *}$, Sri Yuliya ${ }^{2}$, Muhaimin ${ }^{3}$ \\ ${ }^{1 *}, 2$ Pendidikan Matematika Universitas Jambi \\ ${ }^{3}$ Pendidikan IPA Pascasarjana Universitas Jambi \\ *Corresponding author. Address: Departement of Mathematics Education, Universitas Jambi, Jambi \\ E-mail: $\quad$ kamid.fkip@unja.ac.id ${ }^{\left.{ }^{*}\right)}$ \\ sriyuliya8@gmail.com ${ }^{2}$ \\ muhaimin_73@yahoo.de ${ }^{3)}$
}

Received 05 May 2020; Received in revised form 21 June 2020; Accepted 28 June 2020

\begin{abstract}
Abstrak
Penelitian ini bertujuan untuk mengembangkan modul panduan guru dalam mendesain pembelajaran project based learning (PjBL) berbasis budaya Jambi pada materi bangun ruang sisi datar dan untuk mengetahui kelayakan modul panduan guru dilihat dari aspek kevalidan dan aspek kepraktisan. Penelitian ini merupakan penelitian pengembangan yang mengacu pada model pengembangan ADDIE, yaitu analisis, desain, pengembangan, implementasi dan evaluasi. Subjek penelitian ini adalah lima orang guru matematika sebagai praktisi yang berpengalaman dalam mengajar matematika dan berasal dari tempat mengajar yang berbeda. Instrumen yang digunakan untuk mengukur kualitas modul yang dikembangkan meliputi angket tim ahli dan angket presepsi guru. Angket ahli digunakan untuk mengukur kevalidan modul sedangkan angket presepsi guru digunakan untuk melihat kepraktisan modul. Produk penelitian berupa modul panduan guru dalam mendesain pembelajaran project based learning (PjBL) berbasis budaya Jambi pada materi bangun ruang sisi datar. Hasil penelitian pengembangan yang telah dilaksanakan menunjukkan bahwa modul panduan guru yang dikembangkan valid dengan penilaian ahli materi dan ahli desain berupa saran dan komentar yang dikategorikan baik dan layak untuk diujicoba lapangan. Presepsi guru pada modul panduan guru bersifat positif, dari lima praktisi merekomendasikan agar digunakan sebagai panduan guru dalam mendesain pembelajaran project based learning (PjBL) berbasis budaya Jambi di kelas.
\end{abstract}

Kata kunci: Budaya jambi; modul panduan; project based learning (PjBL).

\begin{abstract}
This study aims to develop teacher guide modules in designing learning based on Jambi culture based learning projects $(P j B L)$ on the material flat side spaces and to study teacher learning modules to learn aspects of validity and practical aspects. This research is an interesting development research on the ADDIE development model, namely analysis, design, development, implementation and evaluation. The subjects of this study were five mathematics teachers who participated in the teaching of mathematics and came from different places of teaching. The instrument used to measure the quality of the modules developed adds a questionnaire of expert teams and preset teachers questionnaire. The expert questionnaire was used to measure the module while the teacher's perception questionnaire was used to view the practical module. The research product consists of a teacher guide module in designing learning based on Jambi culture based learning projects $(P j B L)$ on the material on flat side spaces. The results of research on development that have been carried out show that the teacher guide module that is developed is valid with discussion materials and expert design advice and comments that are categorized as good and worthy of field testing. Teacher perceptions in the teacher guide module were positive, from the five shopper arguments to be used as a teacher's guide in designing project-based learning (PjBL) of Jambi culture in the classroom.
\end{abstract}

Keywords: Guide module; jambi culture; project based learning (PjBL). 


\section{PENDAHULUAN}

Panduan pengembangan bahan ajar merupakan langkah awal yang perlu dipelajari ketika mengembangkan bahan ajar. Dengan adanya panduan pengembangan bahan ajar, guru memperoleh gambaran tentang cara membuat bahan ajar. Terlebih dari itu, dengan adanya panduan atau modul pengajaran terbukti dapat meningkatkan profesionalisme bagi guru (Ali \& Mahamod, 2017)

Dengan adanya pandunan penyusunan bahan ajar, guru dapat mengembangkan kemampuan dalam mengolah dan menyesuaikan bahan ajar yang sesuai dengan karakteristik peserta didik. Berbicara terkait karakteristik tentunya, tidak bisa terlepas terhadap unsur budaya daerah setempat, di mana menurut hasil studi budaya dapat mempengaruhi, membentuk karakter (Wahyuni, dkk., 2013; Sultoni dkk, 2015, Oktavianti, 2013).

Integrasi budaya dengan pembelajaran termuat juga dalam Kurikulum 2013 yang menekankan permasalahan nyata dan bisa dibayangkan oleh peserta didik dalam menggunakan contoh-contoh dari lingkungan dimana mereka tinggal. Dalam bidang studi pendidikan matematika, untuk menciptakan lingkungan belajar yang bermakna salah satu caranya dengan mengintegrasi budaya dengan pembelajaran matematika atau etnomatematika (Fajriyah 2018; Rachmawati , 2012; Wahyuni, dkk., 2013).

Budaya jambi mempuyai potensi dan ciri khas yang membutukan sebuah keretifitas untuk mengintegrasikannya dalam pembelajaran matematika. Menurut Kamid, dkk (2016) menyatakan nilai-nilai budaya Jambi yang terdapat dalam kebudayaan melayu Jambi antara lain adalah nilai mata pencarian, nilai kerajinan, nilai kesenian, dan nilai arsitektur bangunan bersejarah.

Pembelajaran project based learning mempunyai karateristik dengan sintak dan jenis projek yang khas, yang membutuhkan konteks dan pemecahan masalah yang menantang bagi siswa. Menurut Wena (2017) Project Based Learning (PjBL) merupakan model pembelajaran yang memberikan kesempatan kepada guru untuk mengolah pembelajaran dikelas dengan melibatkan kerja proyek. Proyek yang dimaksud dapat berupa tugastugas yang kompleks, berbasis masalah atau pertanyaan menantang yang melibatkan peserta didik dalam proses desain, pemecahan masalah, pembuatan keputusan dan puncaknya menghasilan produk nyata atau presentasi dalam bentuk makalah atau laporan. Hal ini juga diperkuat oleh (Timutiasari, dkk 2016; Dianasari, 2015; Diniati, 2015; Ariyana, 2018; Mutmainnah 2016) bahwa model project based learning menekankan pada aktivitas-aktivitas peserta didik untuk belajar diluar kelas yang menghasilkan produk pembelajaran berdasarkan pengalaman nyata yang bersumber pada lingkungan sekitar

Pemilihan konteks matematika yang terintegrasi dengan budaya tentunya mempunyai tanangan tersendiri bagi guru dalam merancang pembelajaran. Hasil observasi ke beberapa guru di sekolah di lingkungan Provinsi Jambi melalui forum diskusi MGMP Matematika, disimpulkan guru belum mempunyai bekal pengetahuan yang cukup untuk membuat, merancang bahan ajar pembelajaran project based learning berbasis budaya Jambi.

Penelitian terkait pengembangan bahan ajar entomatematika (integrasi budaya dan matematika telah banyak 
dilakukan diantaranya dari Cahyaningrum, 2016; Mardiah, 2018; Utami, dkk., 2018; Kurniasari, 2018; Miftakhudin, 2019). Berapa penelitian tersebut mengangkat kontesk budaya dari masing-masing daerah dan ditujukan modul utuk siswa. Tidak banyak terkait topic pengembangan modul untuk guru, diantaranya (Ayriza, 2016) namun penelitian tersebut buakn pada bidang matematika.

Sedangkan untuk kajian entomatematika di budaya Jambi Kamid, dkk (2016) telah melakukan pengembangan perangkat pembelajaran unuk pembelajaran siswa. Bersarkan Hasil kajian literature dan observasi wawancara dengan guru di dapapatkan fakta bahwa belum adanya panduan moduk bagi guru untuk meranncang perangkat pembelajaran matematika berbasis budaya Jambi dan terlebih dengan menggunakan metode PjBL.

Berdasarkan uraian tersebut, maka perlu adanya panduan bagi guru matematika dalam mengembangkan desain pembelajaran poject based learning (PjBL). Tujuan penelitian ini adalah menghasilkan modul panduan guru dalam mendesain pembelajaran project based learning (PjBL) berbasis budaya Jambi pada materi bangun ruang sisi datar".

\section{METODE PENELITIAN}

Research and development (R\&D) ini menggunakan model pengembangan ADDIE yang terdiri dari lima tahap, yaitu Analysis, Design, Development, Implementation, dan Evaluation (Branch, 2009).

Subjek uji coba melibatkan 5 guru-guru matematika di lingkungan sekolah provinsi Jambi yaitu SMP N 7 Muaro Jambi, SMP 1 Kota Jambi, SMP N 22 Kota Jambi dan SMP N 7 Kota Jambi.
Data pertama, berupa data angket yaitu data angket untuk ahli (kriteria valid) dan guru (kriteria praktis). Tabel 1 dan 2 adalah kriteria analisis data dengan menggunakan skala likert.

Tabel 1. Kriteria kevalidan.

\begin{tabular}{cc}
\hline Nilai & Kriteria \\
\hline$X>3,4$ & Sangat valid \\
$2,8 \leq X \leq 3,4$ & Valid \\
$2,2 \leq X \leq 2,8$ & Cukup valid \\
$1,6 \leq X \leq 2,2$ & Kurang valid \\
$X \leq 1,6$ & Sangat kurang valid \\
\hline
\end{tabular}

Tabel 2. Kriteria Tingkat Kepraktisan

\begin{tabular}{cc}
\hline Nilai & Kriteria \\
\hline$X>3,4$ & Sangat praktis \\
$2,8 \leq X \leq 3,4$ & Praktis \\
$2,2 \leq X \leq 2,8$ & Cukup praktis \\
$1,6 \leq X \leq 2,2$ & Kurang praktis \\
$X \leq 1,6$ & Sangat kurang praktis \\
\hline
\end{tabular}

Data kedua, data kualitatif berupa pendapat atau masukan ahli dan persepsi dari subjek terhadap hasil uji coba produk. Data tersebut dianalisis dengan tahapan berikut; 1) mengelola dan mengorganisisr data 2) membaca can mencatat koreksi/revisi 3) mendeskripsikan subtansi koreksi/revisi 4) mendiskusikan tindakan revisi 5) memformulasikan tindakan revisi dan selanjutnya dilakukan revisi (Rusdi,, 2018:245).

\section{HASIL DAN PEMBAHASAN}

Tahap Analysis, tahap ini meliputi analisis kurikulum, analisis materi dan analisis karakteristik guru dan peserta didik. Berdasarkan hasil wawancara guru matematika di SMP Negeri 22 Kota Jambi, kurikulum yang digunakan adalah kurikulum 2013, adapun hasil analisis kompetensi dasar pada materi bangun ruang sisi datar kelas VIII adalah menentukan luas pemukaan dan volume bangun ruang 
sisi datar (kubus, balok, prisma dan limas).

Hasil analisis materi didapat bahwa materi yang akan digunakan adalah materi bangun ruang sisi datar, sedangkan indikator pencapaian kompetensi, peneliti menyesuaikan indikator pencapaian berdasarkan basis budaya Jambi seperti "peserta didik dapat menentukan luas permukaan kubus dan balok melalui pembelajaran proyek berbasis budaya Jambi. Unsur budaya Jambi yang berkaitan dengan bangun ruang sisi datar pada penelitian ini adalah arsitektur bangunan bersejarah, Gentala Arasy, Candi Muaro Jambi dan kerajinan bersejarah yang ada dimuseum Siginjai Jambi. Hasil analisis karakteristik guru dan peserta didik didapat bahwa guru belum pernah menggunakan pembelajaran project based learning (PjBL) berbasis budaya Jambi dan peserta didik masih belum mandiri dalam mengerjakan soal latihan bangun ruang sisi datar.

Tahap Design; pada tahap ini, peneliti menentukan tim pengembangan yang terdiri dari pengembang (peneliti), ahli materi, ahli desain dan lima orang guru matematika. Persiapan pembuatan produk, dimana peneliti mencari dan mengumpulkan beberapa referensi buku, jurnal yang dianggap relevan dan sesuai dengan materi bangun ruang sisi datar yang digunakan dalam mengembangakan modul panduan guru. Setelah mengumpulkan beberapa referensi buku maupun jurnal sebagai panduan dalam membuat modul, selanjutnya peneliti membuat storyboard untuk dijadikan panduan dalam merancang sebuah modul panduan guru dalam mendesain pembelajaran project based learning $(\mathrm{PjBL})$ berbasis budaya Jambi pada materi bangun ruang sisi datar. Desain modul yang peneliti kembangkan terdiri dari sembilan kompenen utama struktur modul yang meliputi:

a. Judul "Modul Panduan Pembelajaran project based learning berbasis budaya Jambi pada materi bangun ruang sisi datar" penulis juga menyertakan identitas penulis dan simbol universitas Jambi serta gambar-gambar budaya Jambi yang terkait dengan bangun ruang sisi datar.

b. Daftar isi. Pada daftar isi berisi daftar topik-topik yang dibahas dalam modul panduan guru dalam mendesain pembelajaran project based learning berbasis budaya Jambi pada materi bangun ruang sisi datar.

c. Petunjuk Penggunaan Modul. Petunjuk penggunaan modul dibuat untuk mempermudah guru dalam menggunakan modul yang telah dibuat.

d. Pendahuluan atau Tinjauan Umum Materi. Pendahuluan pada tiap kegiatan materi pada modul yang peneliti kembangkan berfungsi untuk memberikan gambaran mengenai isi materi yang akan dibahas dan meyakinkan guru bahwa materi yang akan dipelajari bermanfaat.

e. Uraian Materi. Uraian materi pada modul ini berisi empat kegiatan pembelajran yaitu kegiatan belajar 1 berisi materi project based learning (PjBL), kegiatan belajar 2 berisi materi kubus dan balok berbasis budaya Jambi, kegiatan belajar 3 berisi materi prisma berbasis budaya Jambi dan kegiatan belajar 4 berisi materi limas berbasis budaya Jambi. Setiap kegiatan belajar 2, kegiatan belajar 3 dan kegiatan belajar 4 dilengkapi uraian materi yang dihubungkan dengan contoh-contoh budaya Jambi (Gambar 4). 
DOI: https://doi.org/10.24127/ajpm.v9i2.2796
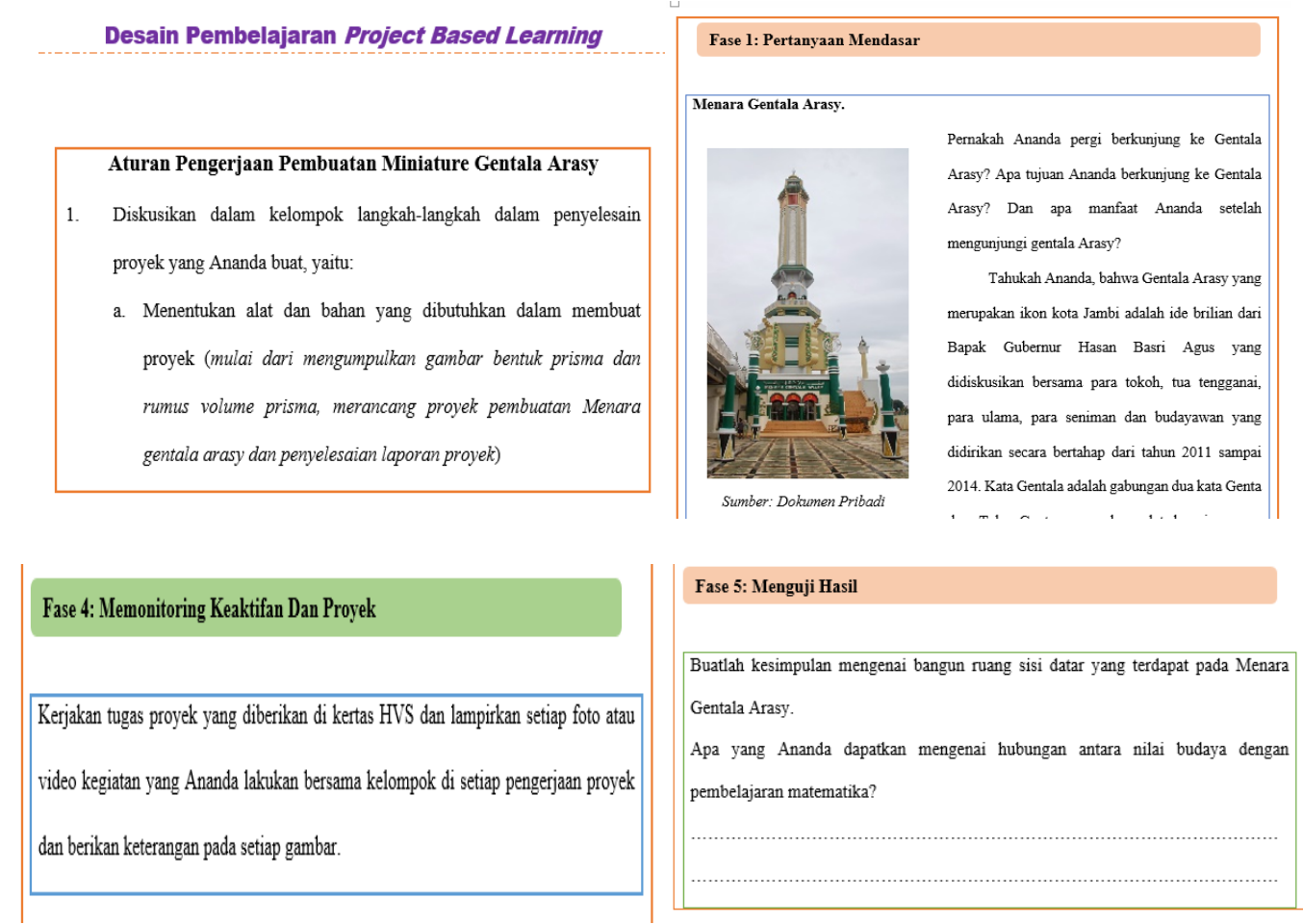

Gambar 4. Tampilan uraian materi modul berdasarkan sintak pembelajaran project based learning berbasis budaya Jambi

f. Rangkuman. Rangkuman pada modul panduan guru berisi informasi dari kesimpulan materi pembelajaran yang telah dibahas pada tiap kegiatan.

g. Penugasan. Penugasan pada modul ini berisi latihan untuk guru dalam mendesain pembelajaran project based learning (PjBL) berbasis budaya Jambi pada materi bangun ruang sisi datar.

h. Tes akhir. Tes akhir pada modul panduan ini berisi umpan balik yang terdiri atas soal-soal pemahaman mengenai materi bangun ruang sisi datar yang dikaitkan pada unsur budaya Jambi.

i. Glosarium. Glosarium berisi definisi konsep bangun ruang sisi data berbasis budaya Jambi yang bertujuan untuk mengingatkan kembali materi yang telah dipelajari.
Tahap Development dan Implementation; pada tahap ini peneliti telah menghasilkan hasil rancangan berupa modul panduan guru, kemudian divalidasi oleh ahli materi, ahli desain dan praktisi. Modul di validasi oleh tim ahli untuk melihat kevalidan dari modul yang dibuat sedangkan praktisi untuk melihat kepraktisan penggunaan modul bagi guru dalam mendesain pembelajaran project based learning (PjBL) berbasis budaya Jambi pada materi bangun ruang sisi datar.

Penilaian modul oleh ahli materi dan ahli desain dilakukan dengan memberikan lembar angket penilaian dilihati dari aspek kelayakan isi, kebahasaan, sajian, desain atau tampilan modul, sintak model project based learning $(\mathrm{PjBL})$, desain isi modul dan kriteria modul. Sedangkan aspek yang dinilai dari praktisi adalah aspek pesan, keterkaitan, posedur pengembangan 
DOI: https://doi.org/10.24127/ajpm.v9i2.2796

modul dan manfaat modul. Selain itu validator memberikan komentar dan saran untuk perbaikan modul yang disajikan pada Tabel 1. Selanjutnya hasil penilaian dan saran digunakan untuk revisi modul.

Tabel 1. Komentar dan saran dari tim ahli.

\begin{tabular}{ll}
\hline \multicolumn{1}{c}{ Validator } & \multicolumn{1}{c}{ Komentar dan Saran } \\
\hline Ahli Materi & $\begin{array}{l}\text { Ahli materi menyarankan untuk membuat lampiran model Gentala } \\
\text { Arasy yang menunjukkan bahwa terdapat unsur prisma pada Gentala } \\
\text { Arasy sebagai pedoman guru. }\end{array}$ \\
\hline Ahli Desain & $\begin{array}{l}\text { Pada cover modul ditambahkan materi matematika yang akan } \\
\text { dikembangkan dalam pembelajaran project based learning berbasis } \\
\text { budaya Jambi }\end{array}$ \\
\hline
\end{tabular}

Berdasarkan hasil penilaian ahli materi, bahasa, dan desain (Tabel 2) pembelajaran dari angket yang diberikan, hanya terdapat beberapa saran perbaikan terhadap modul yang dikembangkan sehingga validator ahli materi, bahasa, dan desain pembelajaran menyatakan bahwa modul yang dikembangkan sudah valid dengan kategori baik dan layak diujicobakan ke lapangan.

Setelah modul panduan guru dalam mendesain pembelajaran project based learning ( $\mathrm{PjBL}$ ) berbasis budaya Jambi pada materi bangun ruang sisi datar dinyatakan baik dan valid oleh ahli materi dan ahli desain pembelajaran, kemudian modul panduan ini diujicobakan kepada praktisi (one to one). Subjek ujicoba adalah 5 guru matematika yang berpengalaman dalam bidang matematika. Lima praktisi memberikan komentar dan saran untuk perbaikan modul yang disajikan pada Tabel 3 .

Hasil penilaian lima praktisi dan small group (Tabel 4) mengenai modul yang dikembangkan; dari segi pesan modul, praktisi menyatakan modul sudah baik dari penggunaan bahasa dan panduan modul dapat berfungsi dengan baik. Dari segi keterkaitan materi bangun ruang sisi datar berbasis budaya Jambi dan prosedur pembelajaran proyek mudah dipahami dan membantu guru dalam mendesain pembelajaran proyek, sedangkan dari segi manfaat modul, praktisi menyatakan modul bermanfaat bagi guru dalam mendesain pembelajaran proyek dan sangat dibutuhkan guru pada pembelajaran abad 21 .

Berdasarkan hasil penilaian lima praktisi disimpulkan bahwa modul panduan guru dalam mendesain pembelajaran project based learning (PjBL) berbasis budaya Jambi pada materi bangun ruang sisi datar memenuhi kategori "praktis". Hal ini sejalan dengan pendapat Plomp, T, \& Nieveen (2010) bahwa media dikatakan praktis jika guru menyatakan produk yang dihasilkan dapat digunakan dan produk mudah digunakan oleh guru sesuai dengan maksud pengembangan.

Tabel 2. Rekapitulasi hasil validasi ahli.

\begin{tabular}{ccc}
\hline No & Ahli & Hasil \\
\hline 1. & Ahli Bahasa & 3,7 \\
2. & Ahli Materi & 3,6 \\
3. & Ahli Media & 3,2 \\
& Rata-Rata & $\mathbf{3 , 5}$ \\
& Kategori & Valid \\
\hline
\end{tabular}


DOI: https://doi.org/10.24127/ajpm.v9i2.2796

Tabel 3. Komentar dan saran dari lima praktisi.

\begin{tabular}{ll}
\hline Validator & \multicolumn{1}{c}{ Komentar dan Saran } \\
\hline Praktisi 1 & $\begin{array}{l}\text { Perbaikan desain grafis untuk memunculakan konteks matematika pada } \\
\text { gambar. }\end{array}$ \\
Praktisi 2 & 1. Ditambahkan petunjuak penggunaan modul untuk guru \\
& 2. Ditambahkan intruksi pembuatan tujuan pembelajaran \\
& 3. Modul panduan guru dibuat kunci jawaban pada lampiran. \\
& 4. Memberikan informasi bahan dan langkah kerja untuk peserta didik. \\
Praktisi 3 & Ditambahkan deskripsi butiran penilaian \\
Praktisi 4 & Memperbaiki intruksi kegiatan PjBL di dalam modul \\
& $\begin{array}{l}\text { Modul yang dikembangkan sangat menarik dan materi modul yang } \\
\text { dihubungkan dengan contoh budaya Jambi bisa menjadi referensi guru } \\
\text { Palam pembelajaran bangun ruang sisi datar, contoh desain pembelajaran } \\
\text { project based learning juga sudah menuntun guru dalam mendesain } \\
\text { pembelajaran proyek }\end{array}$ \\
\hline
\end{tabular}

Tabel 4. Rekapitulasi hasil angket kepraktisan.

\begin{tabular}{ccc}
\hline No & Tahapan & Hasil \\
\hline 1 & One to one & 3,12 \\
2. & Small group & 3,3 \\
& Rata-Rata & $\mathbf{3 , 2 1}$ \\
& Kategori & Praktis \\
\hline
\end{tabular}

Tahap Evaluation; Tahap evaluasi dilakukan pada akhir setiap langkah pengembangan. Evaluasi dilakukan pada proses pembuatan produk hingga produk selesai untuk diujicoba ke lapangan. Hasil akhir dari evaluasi menyimpulkan bahwa modul panduan guru yang dihasilkan valid dan praktis digunakan oleh guru dalam mendesain pembelajaran project based learning $(\mathrm{PjBL})$ berbasis budaya Jambi pada materi bangun ruang sisi datar.

Hasil penelitian menunjukan bahwa guru mererasa terbantu dalam mendisan pembelajaran PjBL berbasis budaya Jambi, membuka sudut pandang potensi-potensi budaya Jambi menjadi konteks pembelajaran matematika. Hasil penelitian ini sejalan juga dengan (Ayriza, 2016) bahwa modul panduan guru dapat meningkatkan profesionalisme guru dalam menyusun bahan ajar. Menurut pendapat subjek penelitian bahan ajar berbasis entnomatemaitka (integrasi budaya dan matmeatika) dapat membuat belajar matematika lebih bermakana. Hal ini juga sejalan dengan penelitian dari (Cahyaningrum, 2016; Mardiah, 2018; Utami, dkk., 2018; Kurniasari,2018; Miftakhudin, 2019).

Penelitian ini memberikan implikasi yaitu melalui modul panduan guru dalam mendesain pembelajaran PjBL berbasis budaya Jambi yang valid dan praktif dapat membantu guru dalam membantu guru dalam mendesain pembelajaran proyek yang berbasis budaya Jambi.

\section{KESIMPULAN DAN SARAN}

Berdasarkan hasil penelitian dapat diambil kesimpulan bahwa modul panduan guru dalam mendesain pembelajaran project based learning (PjBL) berbasis budaya Jambi pada materi bangun ruang sisi datar yang dikembangkan dikategorikan valid dan praktis untuk guru dalam mendesain sebuah pembelajaran proyek.

Adapun saran untuk penelitian selanjutnya hendaknya dapat mengujicobakan modul panduan guru 
dilapangan untuk melihat keefektifitasan modul yang dikembangkan dan memberikan contoh-contoh budaya Jambi yang lebih banyak lagi dari kabupaten-kabupaten di provinsi Jambi lainnya.

\section{DAFTAR PUSTAKA}

Ali, A., \& Mahamod, Z. (2017). Analisis Keperluan terhadap Pengguna Sasaran Modul Pendekatan Berasaskan Bermain bagi Pengajaran dan Pembelajaran Kemahiran Bahasa Kanak-kanak Prasekolah. JuKu: Jurnal Kurikulum \& Pengajaran Asia Pasifik, 3(1), 1-8.

Ariyana, Y. (2018). Buku Pegangan Pembelajaran Berorientasi pada Keterampilan Berfikir Tingkat Tinggi. Jakarta: Kementrian Pendidikan dan Kebudayaan

Ayriza, Y. (2016). Pengembangan Modul Bimbingan Pribadi Sosial Bagi Guru Bimbingan Konseling Untuk Menghadapi Bencana Alam. Jurnal Kependidikan: Penelitian Inovasi Pembelajaran, 39 (2), 141-156.

Branch, R. (2009). Instructional Design: The ADDIE Approach. Springer. USA

Cahyaningrum, N., \& Sukestiyarno, Y. L. (2016). Pembelajaran REACT Berbantuan Modul Etnomatematika Mengembangkan Karakter Cinta Budaya Lokal dan Meningkatkan Kemampuan Pemecahan Masalah. Unnes Journal of Mathematics Education Research, 5(1), 50-59.

Fajriyah, E. (2018). Peran Etnomatematika Terkait Konsep Matematika dalam Mendukung Literasi. In PRISMA, Prosiding Seminar Nasional Matematika, 1, 114-119.
Mardiah, S., \& Rinaldi, A. (2018). Pengembangan Modul Pembelajaran Matematika Berbasis Etnomatematika Menggunakan Metode Inkuiri. Desimal: Jurnal Matematika, 1(2), 119-126.

Dianasari, T. (2015). Pengembangan Modul Pembelajaran Berbasis Proyek Pada Mata Pelajaran Instalansi Penerangan Listrik Untuk Mengetahui Peningkatan Hasil Belajar Siswa Kelas XI TIPTL SMK Negeri 7 Surabaya. Jurnal Pendidikan Teknik Elektro. 4(2), 621-627.

Diniati, A. (2015). Penerapan Pembelajaran Berbasis Proyek Untuk Meningkatkan Kemampuan Berfikir Kritis Siswa Kelas XI 3 SMKN 3 Yogyakarta. Seminar Nasoinal Pendidikan Matematika ke-3. Diakses 11 September 2018.

Kamid, Rohati., Resmiati. (2016). Analisis Nilai-Nilai Budaya Jambi Yang Terkandung Dalam Alat Musik Kelintang Kayu Yang Berkaitan Dengan Pembelajaran Pola Barisan Dan Deret. Aksioma Jurnal Pendidikan Matematika. 5(3), 27-33

Kurniasari, I., Rakhmawati, R., \& Fakhri, J. (2018). Pengembangan E-Module Bercirikan Etnomatematika Pada Materi Bangun Ruang Sisi Datar. Indonesian Journal of Science and Mathematics Education, 1(3), 227-235.

Mutmainnah. (2016). Perbandingan Hasil Belajar Matematika Peserta Didik Melalui Model Pembelajaran Project Based Learning Dan Model Pembelajaran Problem Possing Pada Kelas VIII SMP 1 Parangloe 
DOI: https://doi.org/10.24127/ajpm.v9i2.2796

$\begin{array}{llr}\text { Kabupaten } & \text { Gowa. Skripsi. } \\ \text { Universitas } & \text { Islam Negeri } \\ \text { Alauddin Makasar. Makasar. }\end{array}$ Miftakhudin, M., Purwoko, R. Y., \& Yuzianah, D. (2019). Integrasi Etnomatematika pada Pengembangan E-Modul dengan Pendekatan Saintifik Untuk Menstimulasi Berpikir Logis Siswa SMP. PRISMA, Prosiding Seminar Nasional Matematika, 2, 510-515.

Oktavianti, I., Zuliana, E., \& Ratnasari, Y. (2013). Menggagas kajian kearifan budaya lokal di sekolah dasar melalui gerakan literasi sekolah. Aktualisasi Kurikulum, 35-42

Plomp, T, \& Nieveen, N. (2010). An Introduction to Educational Design Research. SLO Netherlands Institute for Curricullum Development. Netzodruk: Enschede.

Rachmawati, I. (2012). Eksplorasi Etnomatematika Masyarakat Sidoarjo. MATHEdunesa, 1(1).

Rusdi, M. 2018. Penelitian Desain dan Pengembangan Kependidikan. Depok: PT. Raja Grafindo Persada

Sultoni, A., \& Hilmi, H. S. (2015). Pembelajaran Sastra Berbasis Kearifan Lokal Sebagai Upaya Optimalisasi Pendidikan Karakter Kebangsaan Menuju Masyarakat Ekonomi ASEAN (MEA). Prosiding Seminar Nasional Pendidikan Bahasa Indonesia 2015. Surakarta: Universitas Muhammadiyah Surakarta.

Timutiasari, B., dkk. (2016). Pembelajaran Berbasis Proyek Berbantuan Modul Program KRPL untuk Mengembangakan Sikap Peduli Lingkungan dan Keterampilan Proses Sains Siswa
SD Islam Moh. Hatta Malang. Jurnal Pendidikan, 1(6), 11851190.

Utami, R. E., Nugroho, A. A., Dwijayanti, I., \& Sukarno, A. (2018). Pengembangan e-modul berbasis etnomatematika untuk meningkatkan kemampuan pemecahan masalah. JNPM (Jurnal Nasional Pendidikan Matematika), 2(2), 268-283.

Wahyuni, A., Tias, A. A. W., \& Sani, B. (2013), Peran etnomatematika dalam membangun karakter bangsa. Makalah Seminar Nasional Matematika dan Pendidikan Matematika, Prosiding, Jurusan Pendidikan Matematika FMIPA UNY, Yogyakarta: UNY.

$\begin{array}{cr}\text { Wena, M. (2017). } & \text { Strategi } \\ \begin{array}{l}\text { Pembelajaran } \\ \text { Kontenporer. Jakarta: } \\ \text { Group }\end{array} & \text { Media }\end{array}$
Group 